\title{
General practitioners and child protection case conferences
}

\author{
Not attending may be acceptable; not communicating is not
}

General practitioners are poor attenders at child protection case conferences. Lea-Cox and Hall report that in Tower Hamlets only about one in 12 conferences have a general practitioner present (p 1378), ${ }^{1}$ and this low figure is not unique. ${ }^{2}$ Reasons for such poor attendance may be the inconvenient timing of conferences and the inadequate preparation of some participants.

Lea-Cox and Hall's findings, however, suggest that the problems general practitioners have with case conferences may lie deeper than the merely organisational. A psychologist could interpret the wide disparity found in the study between general practitioners' intended, estimated, and actual attendance as avoidance behaviour. How many of the $90 \%$ who regretted not attending case conferences in Tower Hamlets really wanted to attend?

The central function of the case conference is to protect the child. How can general practitioners' attendance at case conferences achieve this? Broadly, they can contribute factual information and give background knowledge of the family. General practitioners are under no legal obligation to attend a case conference or provide medical information about the welfare of a child. They may, however, be open to action for damages in negligence if their failure to provide information prevents the case conference from resolving to protect the child and further abuse occurs (C Tomkins, Medical Defence Union, personal communication). Doctors therefore have a minimum duty to provide factual information that may be crucial in placing a child on the at risk register.

Should doctors be present at all case conferences? Working Together states that "for reasons of efficiency and confidentiality, the number of people involved in the case conference should be limited to those with a need to know, or those who have a contribution to make to the task involved." 3 Two current changes in social work practice need to be considered in relation to attendance by general practitioners. These are the introduction of parental participation and the forthcoming Children Act, with its recognition of parental rights and responsibilities. Also important is the crisis in social services generally, best illustrated by the Social Services Inspectorate's report for London. ${ }^{4}$ (It showed vacancies for posts for social workers in child protection of $17 \cdot 5 \%$ with one in 10 children on at risk registers not allocated to social workers.)

Given this, if there is no significant health problem or obligation to provide evidence and a parent is attending what purpose would attendance by a general practitioner serve? The parent could provide information and help resolve any disputations of fact, with the general practitioner attending only at the request of the parent or child.

The practice of general practitioners "giving references" on families is questionable: perhaps discussions before the case conference between the general practitioner and practice health visitor (who invariably attends) would be preferable. Preserving relationships with all members of the family, especially in suspected child sexual abuse, would be easier if general practitioners were not present. Research suggests that parental participation at initial conferences inhibits professionals, ${ }^{5}$ who tend to decide in favour of parents. ${ }^{6}$ Would a general practitioner be less inhibited in a telephone conversation with a social worker or would that undermine the purpose of parental attendance? Posing such questions is not to undermine the case for general practitioners attending case conferences but to highlight the minefield of child protection procedures and stimulate doctors to re-examine their roles.

What should be done? Firstly, more training is urgently needed. Lea-Cox and Hall's finding that nearly two thirds of general practitioners were confident of their ability to detect sexual abuse ${ }^{1}$ is surprisingly high - suggesting limited understanding of the complexities of diagnosis. Accreditation for the postgraduate education allowance should be given for single and multidisciplinary courses on confidentiality and conflicts of interest, ${ }^{7}$ parental participation, ${ }^{8}$ provision of evidence, and local procedures.

Secondly, family health services authorities need to look imaginatively at ways of facilitating interdisciplinary communications. An example of this is the appointment of a child protection coordinator by Greenwich and Bexley Family Health Services Authority, who is notified of all requests by the social services for general practitioners to attend at case conferences. The coordinator travels to surgeries to type reports from non-attenders and delivers them to the social services (Mai Bunce, personal communication). Family health services authorities also have an important role in drawing up procedural guidelines with local medical committees and local authorities.

Lastly, the participation of local medical committees and family health services authorities in area child protection committees is crucial. These are likely to become proactive and to have considerable authority, with statutory duties to outline local care plans. Although achieving input from general practitioners is not always easy, it is worth while and would be helped if networks of doctors serving area child protection committees could be established.

Non-attendance by general practitioners at most conferences may be acceptable, but non-communication is compatible neither with teamwork nor with child protection. Social workers are not exclusively responsible for child protection; general practitioners need to reassess how best to make their contribution, particularly in the current context of expanding parental participation in case conferences and the problems confronting social workers.

General Practitioner,

ANDREW HARRIS

120 Evelina Road,

London SE15 3HL

1 Lea-Cox C, Hall A. Attendance of general practitioners at child protection case conferences. BMf 1991;302:1378-9.

2 Tudor P. GPs can protect children at risk. Pulse $1979 \mathrm{Dec} 1: 19$

3 Department of Health and Social Security. Working together, a guide to arrangements for inter-agency cooperation for the protection of children from abuse. London: HMSO, 1988.

Social Services Inspectorate. Child protection in London-aspects of management arrangements in social services departments. London: Department of Health, 1990.

5 McGloin P. Turnbull A. Parental participation in child abuse review conferences: a research report. London: London Borough of Greenwich, 1986

6 Dingwall R, Murray $T$, Eekelaar J. Protection of children: state intervention and family life. Oxford: Blackwell, 1983.

7 Department of Health and Social Security. Diagnosis of child sexual abuse; guidance for doctors, appendix B: advice on confidentiality/child abuse from the coordinating committee of the UK defence organisations. London: DHSS, 1988.

8 National Society for the Prevention of Cruelty to Children. Child and parent participation in case conferences. London: NSPCC, 1990. (Occasional paper No 8.) 